\title{
Failure Analysis of Forestry Equipment for Product Improvement in Extreme Environments
}

\author{
Daniel Thomas
}

Submitted: 29 September 2020/ Accepted: 2 October 2020/Published online: 21 October 2020

(c) ASM International 2020

The profession of failure analysis offers continuous opportunities for product improvement. This provides stimulating work that is vital toward keeping people safe and enhancing product reliability. For many years, I have been fascinated by the development of new heavy goods vehicles, agricultural equipment and forestry machinery. This fascination recently took me to Northern Canada, a region where even the hardiest of souls' fear to tread. During service, equipment used in these regions will often experience operational scenarios that were never at first envisaged by the equipment manufacturer. However, with an understanding of failure modes in the field every generation of machine will be better that the last. This is through the process of continuous improvement and product enhancement.

There is as a result an opportunity to learn what is happening in the field and then develop products around these sets of criteria, particularly when such equipment operates in extreme environments. Loggers are a tough breed and they say that when logging gets in your blood it is there forever. There are generations of loggers who will tell you of this. As a result, the equipment must be capable of being operated by some of the toughest people in the world. During my time working in this domain, we studied the operation and failures that occurred in the field. This work studied an array of vehicles, including feller bunchers, yarders, forwarders, harvesters, log loaders and traditional excavators. By their nature, such equipment is designed to last a long time. However, aging equipment will often fail in regions not originally envisaged by the

D. Thomas $(\square)$

Creation Engineering Group, Cardiff, Wales

e-mail: daniel.thomas@creationengineering.co.uk designers. Because of this, initial failure mode analysis has to initially be carried out in the field.

Safety critical equipment and systems are exposed to extreme weather, operational loads that exceed those specified and all while doing an unpredictable job. In the forests of Northern Canada, temperatures can be as low as $-35^{\circ} \mathrm{C}$ and it is true to say that it is where the extremes of nature are pitted against both man and machine. That is why logging is the most dangerous job in the world [1].

Developing a product around the needs of the user is wise and what can be learned from them is important in product enhancement [2]. Particularly when a product fails, a manufacturer will learn from this and it can be made better. Particularly, for yellow goods and forestry equipment, the quality of the product line keeps on improving, making the job safer and helping to make work more efficient. A few different types of FMEA analyses exist that can help us [3]. The function of equipment can be adjusted, it be can design with further refinement and/or the manufacturing method can be further improved. Recent considerations are in which advanced high-strength steel grades are used or even if newer composite materials can be integrated into new designs? These all help is reducing stress on components and/or increasing the minimum safety tolerance through design are also considered.

Working on the product improvement requires the process of reducing the probability of failure on certain areas of a structure. Therefore, it is important to understand how a product is used. Mechanical and structural failures are common in the field with repair being carried out correctively, but lessons learned often lost. Often such vehicles are exposed to loads and environments that often were never envisaged. Lessons learned become extremely important. Welds often become the sites of failure; however, broken tracks, distortion, corrosion, cut edges and 


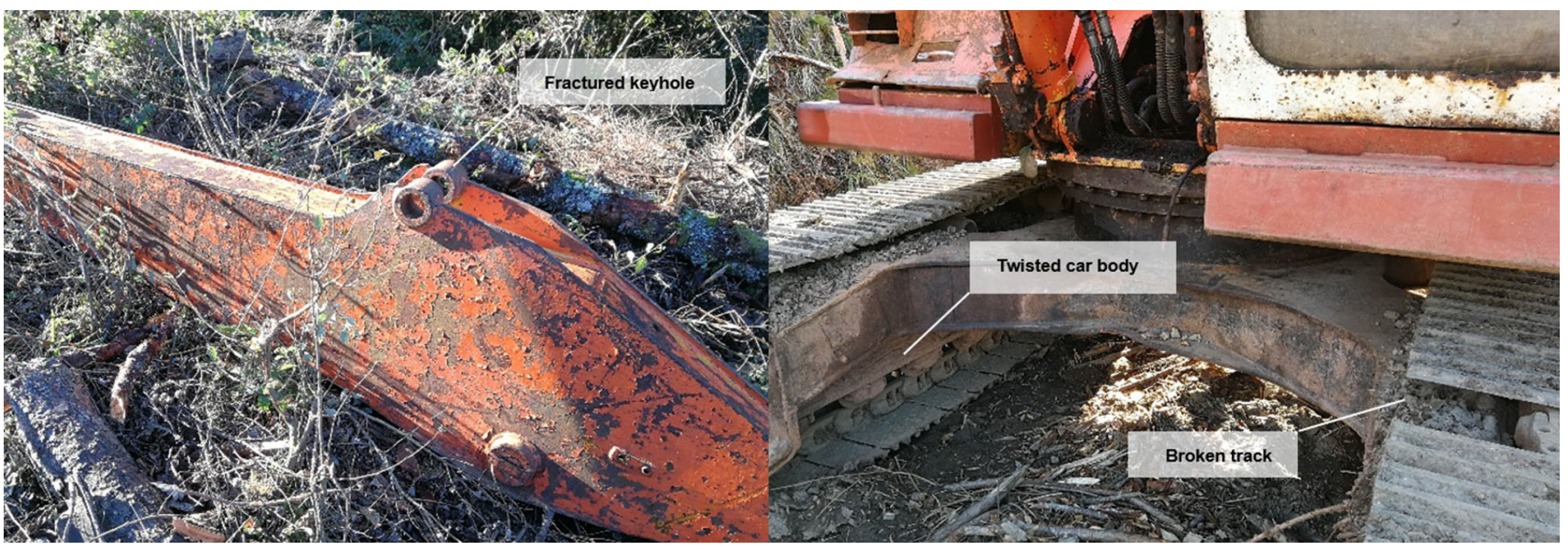

Fig. 1 Onsite inspection of a 360-degree excavator (left) a broken arm and (right) broken track and twisted car body

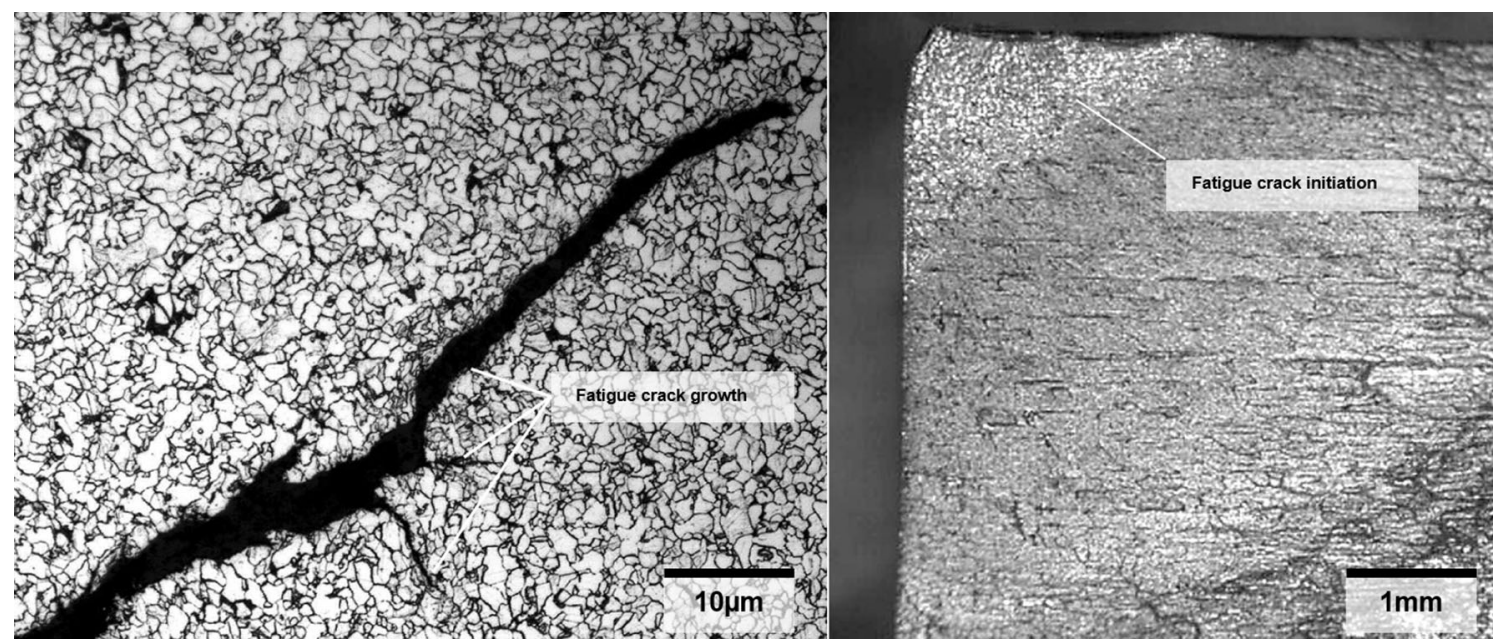

Fig. 2 Optical light microscope of the grain structure reveled with 5\% Nital etch and fracture surface of S275 steel grade. The fracture was from a fatigue induced failure that caused the destruction of the excavator arm

numerous other issues can happen during operations. Brittle fracture can often be found in vehicles that are operated in extremely low temperatures. This is particularly important in the case when determining whether conventional S275 and S355 structural steel grades can be substituted for newer S700, DP600 or DP1400 advanced high-strength steel grades. There are also further opportunities for the combination of newer materials together with product redesign and enhancement.

Important questions are often asked, such as can maintenance schedules be adjusted for equipment and particularly recommendations for inspection of parts that are known to fail in service. Looking for the regions where something has failed, and then, subsequently using key techniques to failure analysis is vital. One example is shown in Fig. 1 in which an eight-year-old 30-ton excavator was found to have multiple failures. The unit had been redesigned and modified for forestry clearing work and building of vehicle access roads.

Basic analysis in the field is often carried out using my trusty wire brush and USB microscope. In the field, this was carried out to quickly find the point of failure. Sections of material where fractures can be removed can then further subjected to detailed optical microscope and scanning electron microscope (SEM) analysis later in the laboratory as shown in Fig. 2. In this case, it was later identified that dross from a plasma cut panel in the factory had been the initiation point for a fatigue crack. This crack would have been invisible and impossible to spot by the user; however, it continued to grow along the length of the steel before sudden fracture of the whole structure occurred. Because the vehicle had worked in extremely cold temperatures for most of its life, the fatigue crack was 
Fig. 3 Using failure analysis data to redesign future models of equipment and optimize them so they have enhanced durability
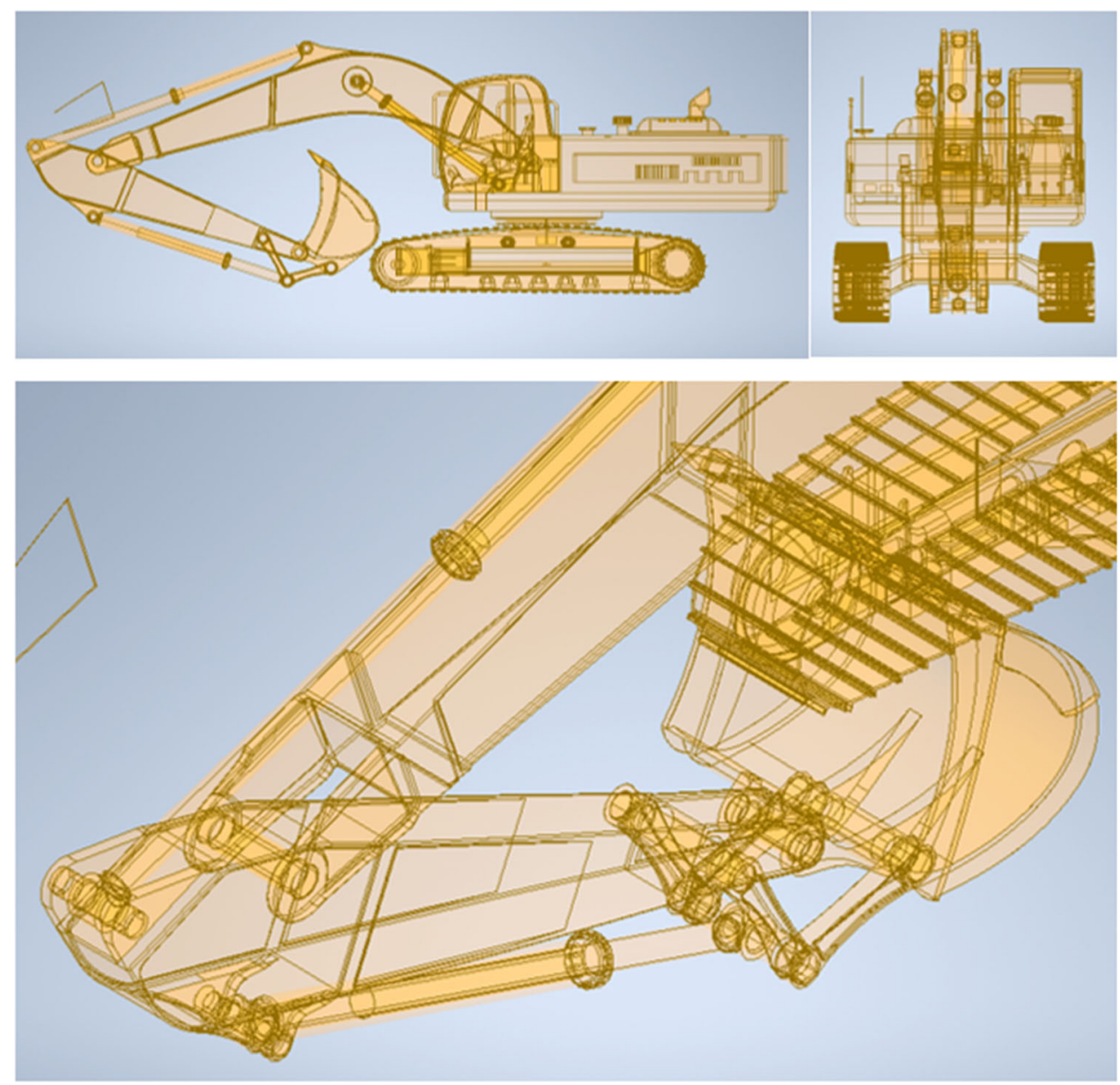

observed to be brittle and had grown in an intergranular fashion through the steel microstructure.

With all this information, we can go back and determine the sources of failure and often map this to the cumulative causes. Further work on computer-aided engineering as shown in Fig. 3 can then be carried out. Here, components that have failed can be redesigned and simulated with complex loading or environmental criteria.

This continuous improvement of equipment demonstrates that analysis of failures offers a valuable tool for improving the product life and integrity.

\section{References}

1. The Top 10 Most Dangerous \& Hazardous Jobs in 2019 https:// www.themarlincompany.com/blog-articles/dangerous-jobs-2019/. Accessed 20 Oct 2020

2. H. Jurgens. Safety analysis of an electronic equipped ground drive system for an self proppeled agricultural machine by using the FMEA-method", in Proceedings of the Conference on Agricultural Engineering, vol 1636, 2001, pp. 59-61

3. STN IEC 60812 (010675):2006-2010 Analysis techniques for system reliability. Procedure for failure mode and effects analysis (FMEA)

Publisher's Note Springer Nature remains neutral with regard to jurisdictional claims in published maps and institutional affiliations. 